\title{
Role of Glucagon, Catecholamines, and Growth Hormone in Human Glucose Counterregulation
}

\author{
EFFECTS OF SOMATOSTATIN AND COMBINED $\alpha$-AND $\beta$-ADRENERGIC \\ BLOCKADE ON PLASMA GLUCOSE RECOVERY AND GLUCOSE FLUX RATES
} AFTER INSULIN-INDUCED HYPOGLYCEMIA

\author{
Robert A. Rizza, Philip E. Cryer, and John E. Gerich, Diabetes and Metabolism \\ Research Laboratory, Endocrine Research Unit, Departments of Medicine and \\ Physiology, Mayo Medical School and Mayo Clinic, Rochester, Minnesota 55901; \\ Metabolism Division, Department of Medicine, Washington University School of \\ Medicine, St. Louis, Missouri 63110
}

\begin{abstract}
A B S T R A C T To further characterize mechanisms of glucose counterregulation in man, the effects of pharmacologically inducd deficiencies of glucagon, growth hormone, and catecholamines (alone and in combination) on recovery of plasma glucose from insulin-induced hypoglycemia and attendant changes in isotopically $\left(\left[3-{ }^{3} \mathrm{H}\right]\right.$ glucose $)$ determined glucose fluxes were studied in 13 normal subjects. In control studies, recovery of plasma glucose from hypoglycemia was primarily due to a compensatory increase in glucose production; the temporal relationship of glucagon, epinephrine, cortisol, and growth hormone responses with the compensatory increase in glucose appearance was compatible with potential participation of all these hormones in acute glucose counterregulation. Infusion of somatostatin (combined deficiency of glucagon and growth hormone) accentuated insulin-induced hypoglycemia (plasma glucose nadir: $36 \pm 2 \mathrm{ng} / \mathrm{dl}$ during infusion of somatostatin vs. $47 \pm 2 \mathrm{mg} / \mathrm{dl}$ in control studies, $P<0.01)$ and impaired restoration of normoglycemia (plasma glucose at $\min 90: 73 \pm 3 \mathrm{mg} / \mathrm{dl}$ at end of somatostatin infusion vs. $92 \pm 3 \mathrm{mg} / \mathrm{dl}$ in control studies, $P<0.01)$. This impaired recovery of plasma glucose was due to blunting of the compensatory increase in glucose appearance since glucose disappearance was not augmented, and was attributable to suppression of
\end{abstract}

This work was presented in part at the National Meeting of the American Federation of Clinical Research, San Francisco, Calif., 29 April-1 May 1978.

Received for publication 6 December 1978 and in revised form 16 March 1979. glucagon secretion rather than growth hormone secretion since these effects of somatostatin were not observed during simultaneous infusion of somatostatin and glucagon whereas infusion of growth hormone along with somatostatin did not prevent the effects of somatostatin. The attenuated recovery of plasma glucose from hypoglycemia observed during somatostatininduced glucagon deficiency was associated with plasma epinephrine levels twice those observed in control studies. Infusion of phentolamine plus propranolol (combined $\alpha$ - and $\beta$-adrenergic blockade) had no effect on plasma glucose or glucose fluxes after insulin administration. However, infusion of somatostatin along with both phentolamine and propranolol further impaired recovery of plasma glucose from hypoglycemia compared to that observed with somatostatin alone (plasma glucose at end of infusions: $52 \pm 6 \mathrm{mg} / \mathrm{dl}$ for somatostatin-phentolamine-propranolol vs. $72 \pm 5$ $\mathrm{mg} / \mathrm{dl}$ for somatostatin alone, $P<0.01$ ); this was due to further suppression of the compensatory increase in glucose appearance (maximal values: $1.93 \pm 0.41 \mathrm{mg} / \mathrm{kg}$ per min for somatostatin-phentolamine-propranolol vs. $2.86 \pm 0.32 \mathrm{mg} / \mathrm{kg}$ per min for somatostatin alone, $P<0.05)$. These results indicate that in man $(a)$ restoration of normoglycemia after insulin-induced hypoglycemia is primarily due to a compensatory increase in glucose production; $(b)$ intact glucagon secretion, but not growth hormone secretion, is necessary for normal glucose counterregulation, and $(c)$ adrenergic mechanisms do not normally play an essential role in this process but become critical to recovery from hypoglycemia when glucagon secretion is impaired. 


\section{INTRODUCTION}

Plasma levels of glucagon (1), catecholamines (2), growth hormone (3), and cortisol (4) increase during hypoglycemia in man. Although each of these has metabolic actions which may potentially reverse hypoglycemia (5-8), their individual contribution to the restoration of normoglycemia remains to be established.

Using a sensitive isotope derivative method, Garber et al. (9) noted that early increments in plasma catecholamine concentrations during insulin-induced hypoglycemia in human subjects preceded the major compensatory changes in glucose fluxes raising the possibility that adrenergic mechanisms may be important in initiating glucose counterregulation. However, factors other than catecholamines must be capable of restoring normoglycemia because apparently normal glucose counterregulation has been observed in catecholamine-deficient patients with spinal cord transections $(10,11)$, epinephrine-deficient adrenalectomized patients (11-14), and normal subjects during the infusion of $\alpha$ - or $\beta$-adrenergic blocking agents (15-17).

It is commonly thought that glucagon, growth hormone, and cortisol also play some role in acute glucose counterregulation. The administration of somatostatin, an inhibitor of glucagon and growth hormone secretion, impairs but does not prevent recovery of plasma glucose from hypoglycemia in baboons and normal man $(13,18,19)$. Notably, however, somatostatin infusion does prevent recovery of plasma glucose from hypoglycemia in dexamethasone-treated adrenalectomized patients (13). Although chronic growth hormone and cortisol excess may cause resistance to the actions of insulin $(20,21)$, the importance of acute changes in growth hormone and cortisol secretion in counteracting the acute hypoglycemic action of insulin can be questioned because normal plasma glucose recovery from insulin-induced hypoglycemia has been observed under conditions in which acute release of these hormones was not possible $(12-14,22,23)$.

These considerations led us to hypothesize that glucagon plays the primary role in acute recovery of plasma glucose from insulin-induced hypoglycemia and that adrenergic mechanisms, probably activated by adrenomedullary epinephrine, play a secondary role since they appear to be capable of partially compensating for glucagon lack (13). To test this hypothesis, plasma glucose recovery from insulin-induced hypoglycemia along with isotopically determined rates of glucose appearance and disappearance and the circulating concentrations of glucagon, epinephrine, norepinephrine, cortisol, and growth hormone were determined in normal human subjects during: $(a)$ infusion of saline (control); $(b)$ infusion of somatostatin (combined glucagon and growth hormone deficiency); (c) infusion of somatostatin plus glucagon (growth hormone deficiency); $(d)$ infusion of somatostatin plus growth hormone (glucagon deficiency); $(e)$ infusion of propranolol plus phentolamine (adrenergic blockade); and $(f)$ infusion of somatostatin plus propranolol and phentolamine (combined glucagon and growth hormone deficiency and adrenergic blockade).

\section{METHODS}

Informed written consent was obtained from 13 healthy adult volunteers ( 8 women, 5 men, whose ages range from 19 to 47). All were within $10 \%$ of their ideal body weight (Metropolitan Life Insurance Tables), and had no family history of diabetes mellitus.

Subjects were admitted to the outpatient facility of the Mayo Clinic General Clinical Research Center between 7:00 and 8:00 a.m. having fasted overnight $(10-12 \mathrm{~h})$. The subjects were placed at bed rest, and an antecubital vein of each of their arms was cannulated with 18-gauge catheters, one for drug administration and the other for blood sampling. For isotopic determination of glucose appearance and disappearance rates, a primed $(14 \mu \mathrm{Ci})$ continuous $(0.14 \mu \mathrm{Ci} / \mathrm{min})$ infusion of $\left[3-{ }^{3} \mathrm{H}\right]$ glucose (New England Nuclear, [Boston, Mass.] sp act $17.54 \mathrm{Ci} / \mathrm{mM}$, made up in $0.9 \% \mathrm{NaCl}, 50 \mu \mathrm{Ci} / \mathrm{ml}$ ) was begun; $2 \mathrm{~h}$ were allowed for isotope equilibration before all experiments.

In the first series of experiments, seven subjects (five women, two men) were studied on four occasions each separated by at least $48 \mathrm{~h}$. The order of the studies was randomized. In all experiments, at time 0 each subject was given an intravenous bolus injection of $0.04 \mathrm{U} / \mathrm{kg}$ regular insulin (Eli Lilly and Company, Indianapolis, Ind.). On separate days beginning at time 0 , subjects were administered either (a) $0.9 \% \mathrm{NaCl}, 0.19 \mathrm{ml} / \mathrm{min}$; $(b)$ somatostatin alone, $250 \mu \mathrm{g} / \mathrm{h}$ (courtesy of Dr. Jean Rivier and Dr. Roger Guillemin, Salk Institute, San Diego, Calif.) infused for $90 \mathrm{~min}$; (c) somatostatin as above plus glucagon (Eli Lilly and Company) $3 \mathrm{ng} / \mathrm{kg}$ per $\mathrm{min}$ for $60 \mathrm{~min}$; or $(d)$ somatostatin as above plus human growth hormone (National Pituitary Agency lot 11-31 -Wilhelmi, $1.4 \pm I U / \mathrm{mg}$ ), $10 \mu \mathrm{g} / \mathrm{kg}$ per $\mathrm{h}$ for $90 \mathrm{~min}$. In the second series of experiments, six subjects (three women, three men) received in addition to insulin $(0.04 \mathrm{U} / \mathrm{kg})$ intravenous infusions of either $(a) 0.9 \% \mathrm{NaCl}, 0.19 \mathrm{ml} / \mathrm{min}$; $(b)$ somatostatin $(250 \mu \mathrm{g} / \mathrm{h}$ for $90 \mathrm{~min}) ;(c)$ phentolamine (Ciba Pharmaceutical Company, Summit, N. J.), 5 mg over 2 min followed by $500 \mu \mathrm{g} / \mathrm{min}$ for $90 \mathrm{~min}$ plus propranolol (Ayerst Laboratories, New York), $5 \mathrm{mg}$ over $2 \mathrm{~min}$ followed by 80 $\mu \mathrm{g} / \mathrm{min}$ for $90 \mathrm{~min}$; or $(d)$ a combination of somatostatin, propranolol, and phentolamine in the doses and at the times indicated above. All reagents were dissolved in $0.9 \% \mathrm{NaCl}$ containing $1 \mathrm{~g} / 100 \mathrm{ml}$ human serum albumin (Cutter Laboratories, Inc., Berkeley, Calif.) on the morning of each experiment and were infused at a rate of $0.19 \mathrm{ml} / \mathrm{min}$.

Blood samples were obtained every $10 \mathrm{~min}$ for $60 \mathrm{~min}$ and at 15-min intervals thereafter for an additional $60 \mathrm{~min}$. Samples for glucagon, cortisol, and growth hormone were collected in chilled tubes containing $17 \mathrm{mg}$ EDTA and $0.5 \mathrm{M}$ benzamidine (Sigma Chemical Co., St. Louis, Mo.). Blood for catecholamine determinations was collected in chilled heparinized tubes containing $20 \mathrm{mg}$ reduced glutathione (Sigma Chemical Co.). Blood for plasma glucose and glucose specific activity was collected in $\mathrm{NaF}$-oxalate tubes (KimbleTerumo, Elkton, Md.); an aliquot of this plasma was used for determination of glucose concentration in duplicate 


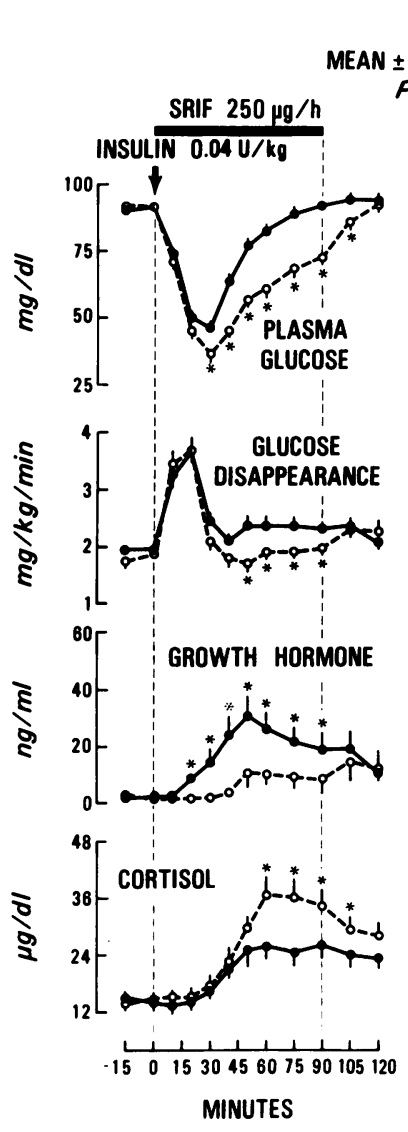

$\longrightarrow$ SALINE

$P<0.05$
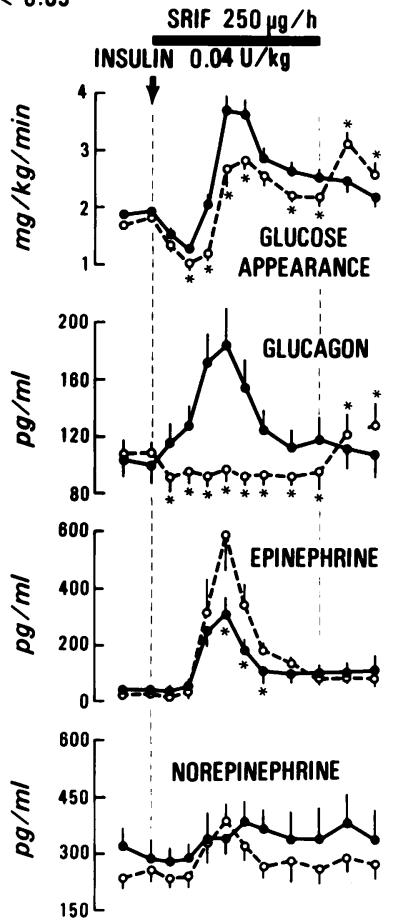

$\begin{array}{rrrrrrrrr}15 & 1 & 1 & 1 & 1 & 1 & 1 \\ -15 & 0 & 153045607590105120\end{array}$ MINUTES

FIGURE 1 Effects of somatostatin (SRIF) infusion (combined glucagon and growth hormone deficiency) on plasma glucose, glucagon, growth hormone, cortisol, epinephrine, norepinephrine levels and the rates of glucose appearance and disappearance after insulin administration.

(Yellow Springs Instrument Co., Yellow Springs, Ohio, A23), and another aliquot $(1.6 \mathrm{ml})$ was deproteinized by addition of $0.3 \mathrm{ml}$ chilled $3 \mathrm{M}$ perchlorate for subsequent determination of glucose radioactivity. All blood samples for hormone determinations were centrifuged immediately after each experiment, and the resultant plasma was stored at $-20^{\circ} \mathrm{C}$ until assay.

Plasma $\left[3-{ }^{3} \mathrm{H}\right]$ glucose specific activity was determined as follows: duplicate $0.4-\mathrm{ml}$ aliquots of deproteinized plasma were evaporated to dryness at $37^{\circ} \mathrm{C}$ under compressed air to remove tritiated water. The residue was resuspended with $0.5 \mathrm{ml}$ distilled water, and after addition of $10 \mathrm{~cm}^{3}$ Aquasol (New England Nuclear), its radioactivity was counted in a refrigerated liquid scintillation spectrometer. Correction for quenching was made using the method of external standard ratios. The average glucose radioactivity of each plasma sample was divided by its glucose concentration to obtain glucose specific activity. Calculated infusion rates of the isotope were verified by measuring the volume of the $\left[3-{ }^{3} \mathrm{H}\right]$ glucose infusate before and after each experiment.

Plasma growth hormone (24) and glucagon (25) (Unger $30 \mathrm{~K}$ antibody) were determined by radioimmunoassay. Plasma corticoids were measured by the competitive protein binding method of Murphy (26). Plasma catecholamines were assayed using a single-isotope derivative method based on the en-

zymatic conversion of the catecholamines to their respective labeled metanephrines as previously described (27).

Rates of glucose appearance and disappearance were calculated employing the equations of Wall et al. (28) as modified by DeBodo et al. (29). This method has been shown to accurately reflect glucose kinetics over a wide range of nonsteady-state plasma glucose levels (30). All data in the text and figures are expressed as mean $\pm S E M$, and their statistical significance was evaluated using Student's two tailed paired $t$ test (31).

\section{RESULTS}

Control studies (Fig. 1). All 13 subjects participated in both control and somatostatin studies; their data are shown in Fig. 1. In the control studies in which saline alone was infused after insulin administration, intravenous injection of $0.04 \mathrm{U} / \mathrm{kg}$ insulin resulted in a prompt decrease in plasma glucose from base-line values to a nadir at $30 \mathrm{~min}$. By $85 \mathrm{~min}$ plasma glucose returned to levels not significantly different from baseline values. Glucose disappearance increased after insulin administration from a basal rate of $1.92 \pm 0.06 \mathrm{mg} /$ $\mathrm{kg}$ per min to a maximum of $3.65 \pm 0.21 \mathrm{mg} / \mathrm{kg}$ per min at min 20; subsequently glucose disappearance decreased but remained consistently above basal values from $\min 40$ through $\min 120$. Glucose appearance decreased after insulin administration from a basal rate of $1.93 \pm 0.05 \mathrm{mg} / \mathrm{kg}$ per min to a nadir of $1.26 \pm 0.11$ $\mathrm{mg} / \mathrm{kg}$ per min at min 20 . This was followed by an increase in glucose appearance above base-line values to a maximum of $3.70 \pm 0.24 \mathrm{mg} / \mathrm{kg}$ per min at min 40 . Subsequently, glucose appearance decreased over the next 80 min but was still significantly greater than basal values at min $120(2.17 \pm 0.14, P<0.01)$.

After insulin administration, plasma glucagon increased from a basal value of $99 \pm 12$ to $131 \pm 13 \mathrm{pg} / \mathrm{ml}$ at $\min 20(P<0.001)$, reached a maximum at $\min 40$, and subsequently decreased to near basal values at min 90 . Statistically significant increases in plasma epinephrine $(P<0.001)$, cortisol $(P<0.05)$, and growth hormone $(P<0.01)$ were not observed until min 30 . Increases in plasma norepinephrine were not statistically significant until min $50(P<0.005)$. Plasma epinephrine reached maximum levels at min 40 and subsequently decreased toward base-line concentrations; values at min 120 were still significantly $(P<0.01)$ above base-line levels. Plasma cortisol, growth hormone, and norepinephrine reached maximum levels at min 50-60 and remained significantly $(P<0.05-0.01)$ above basal values through min 120 .

Effect of somatostatin infusion-combined growth hormone and glucagon deficiency (Fig. 1). To evaluate the contribution of acute changes in glucagon and growth hormone secretion to glucose counterregulation, somatostatin was infused for $90 \mathrm{~min}$ after insulin administration to prevent glucagon and growth hormone responses. Somatostatin suppressed plasma 
glucagon slightly below basal levels throughout its infusion; over this interval plasma glucagon levels averaged $95 \pm 5 \mathrm{pg} / \mathrm{ml}$ compared to basal values of $108 \pm 9 \mathrm{pg} / \mathrm{ml}, P<0.001$. Somatostatin did not suppress plasma growth hormone below basal levels but did impair its increase after insulin-induced hypoglycemia.

In the somatostatin studies, plasma glucose decreased after insulin administration to a nadir of $36 \pm 2 \mathrm{mg} / \mathrm{dl}$ which was significantly lower than that observed in the control studies $(47 \pm 2 \mathrm{mg} / \mathrm{dl}, P<0.001)$. All subsequent plasma glucose values during infusion of somatostatin were also significantly less than those observed in the control studies, $P<0.01$. The initial increase in glucose disappearance after insulin injection was virtually identical in both somatostatin and control studies; after min 40, however, glucose disappearance was significantly less in the somatostatin studies than that observed in the control studies until discontinuation of the somatostatin infusion. The initial decrease in glucose appearance after insulin administration was greater in the somatostatin studies; glucose appearance decreased from a base-line rate to a nadir of $1.02 \pm 0.11 \mathrm{mg} / \mathrm{kg}$ per min at min 20 which was significantly lower than that observed in the control studies $(1.26 \pm 0.11 \mathrm{mg} / \mathrm{kg}$ per $\min , P<0.05)$. The subsequent increase in glucose appearance above base-line values was less than that observed in the control studies; the maximum value reached in the somatostatin studies was $2.86 \pm 0.18 \mathrm{mg} / \mathrm{kg}$ per min at min 50 compared to the maximum of $3.71 \pm 0.24 \mathrm{mg} / \mathrm{kg}$ per min at min 40 in the control studies $(P<0.001)$. When the somatostatin infusion was stopped, glucose appearance abruptly increased; this was accompanied by an increase of plasma glucose to base-line values.

Both plasma cortisol and plasma epinephrine increased to greater levels in the somatostatin studies; peak values for plasma cortisol averaged $37 \pm 4$ compared to $26 \pm 3 \mu \mathrm{g} / \mathrm{dl}$ in the control studies $(P<0.05)$. Peak values for plasma epinephrine averaged $582 \pm 108$ compared to $310 \pm 41 \mathrm{pg} / \mathrm{ml}$ in control studies $(P<0.01)$. There was no significant difference in plasma norepinephrine responses in the two studies.

Effect of infusion of somatostatin plus growth hormone-glucagon deficiency (Fig. 2). Because infusion of somatostatin in the preceding studies produced combined deficiency of glucagon and growth hormone, in the following study growth hormone was infused along with somatostatin in seven subjects to evaluate the effect of glucagon deficiency in the absence of growth hormone deficiency. During infusion of somatostatin plus growth hormone $(10 \mu \mathrm{g} / \mathrm{kg}$ per $\mathrm{min}$ ), plasma growth hormone increased progressively from a basal level of $2.0 \pm 0.6 \mathrm{ng} / \mathrm{ml}$ to stable levels of $54-58 \mathrm{ng} / \mathrm{ml}$ between $\min 60$ and $\min 90$, values 2 - to 3 -fold greater than those observed in control studies $(22-29 \mathrm{ng} / \mathrm{ml}, P<0.01)$ and 10 - to 15 -fold greater than

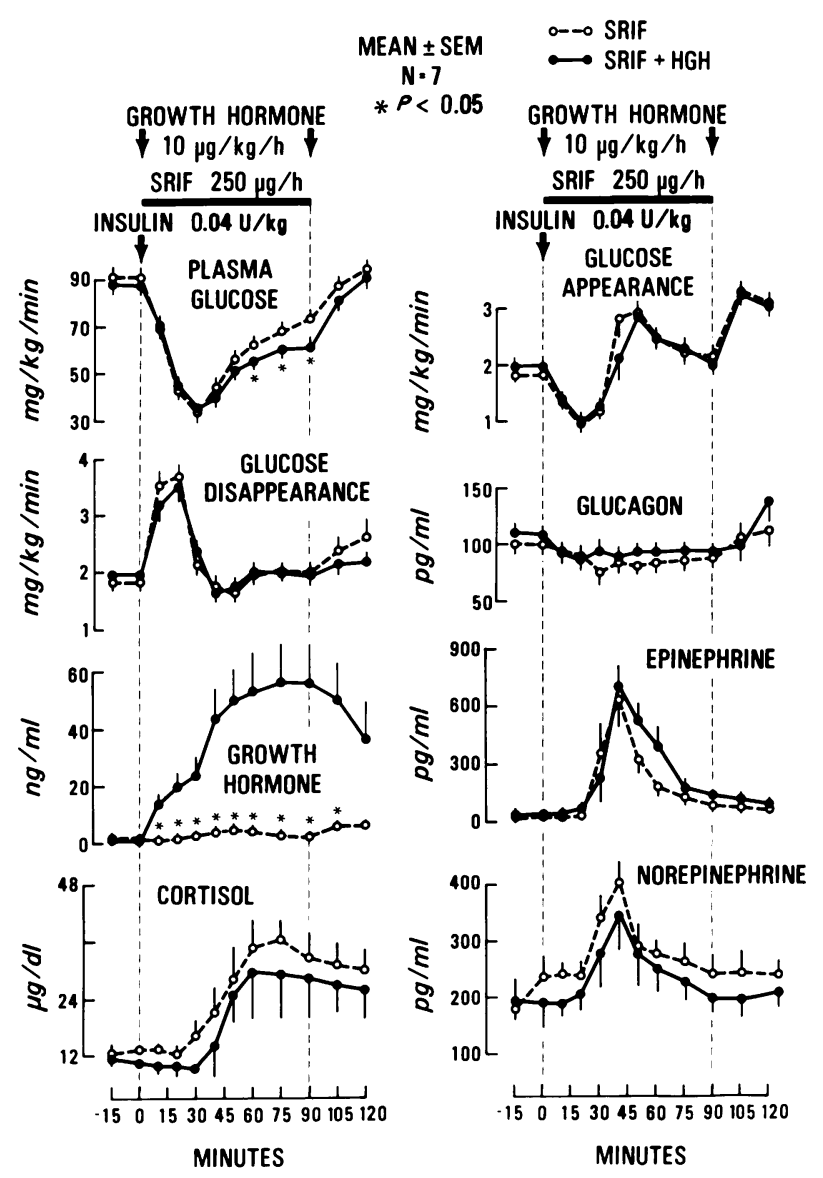

FIGURE 2 Effects of growth hormone replacement (glucagon deficiency) on somatostatin (SRIF)-induced alterations in plasma glucose, glucagon, growth hormone, cortisol, epinephrine, norepinephrine levels and the rates of glucose appearance and disappearance after insulin administration.

those observed during infusion of somatostatin alone $(3-5 \mathrm{ng} / \mathrm{ml}, P<0.001)$ in the same subjects. Plasma glucagon levels remained suppressed during the 90min infusion period to the same extent as they had been during infusion of somatostatin alone.

This infusion of growth hormone, leaving a somatostatin-induced glucagon deficiency, did not reverse the effect of somatostatin on plasma glucose recovery from insulin-induced hypoglycemia nor did it significantly alter the changes in glucose appearance and disappearance or those of plasma epinephrine, norepinephrine, and cortisol levels from those observed during infusion of somatostatin alone. Indeed despite no statistically significant differences in glucose appearance and disappearance or in counterregulatory hormone responses, plasma glucose levels were significantly less from min 60 through min 90 during infusion of growth hormone plus somatostatin than during infusion of somatostatin alone, $P<0.01$.

Effect of infusion of somatostatin plus glucagon 


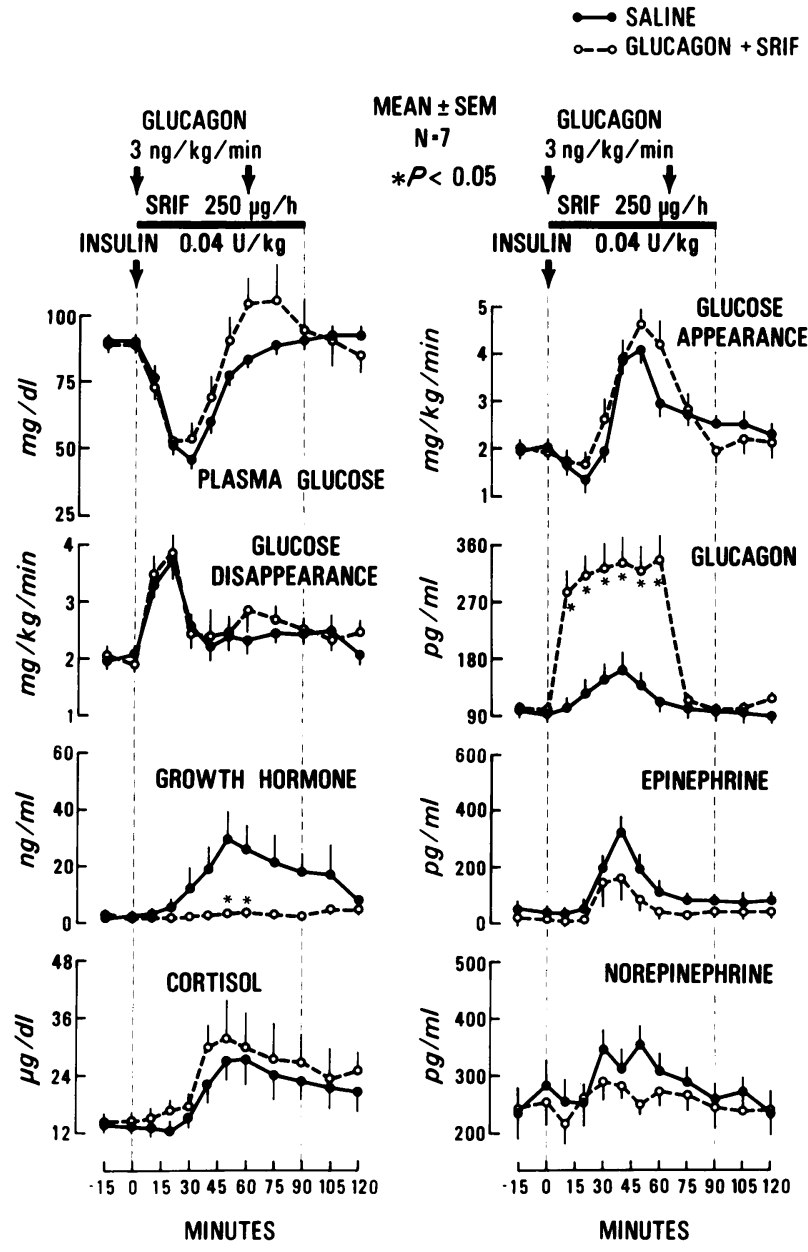

FIGURE 3 Effects of glucagon replacement (growth hormone deficiency) on somatostatin (SRIF)-induced alterations in plasma glucose, glucagon, growth hormone, cortisol, epinephrine, norepinephrine levels and the rates of glucose appearance and disappearance after insulin administration.

- growth hormone deficiency (Fig. 3). To evaluate the effect of growth hormone deficiency in the absence of glucagon deficiency, somatostatin was infused in the seven subjects studied above along with glucagon at a rate estimated to reproduce portal venous glucagon responses which had occurred during control studies. A portal-peripheral venous gradient of 2.2 was assumed based on previous reports $(32,33)$ of measurements of glucagon levels in portal and peripheral venous blood samples obtained simultaneously during stimulation of glucagon secretion. Infusion of glucagon at a rate of $3 \mathrm{ng} / \mathrm{kg}$ per min for $60 \mathrm{~min}$ increased circulating glucagon from basal values $\cong 100$ $\mathrm{pg} / \mathrm{ml}$ to levels averaging between 290 and $320 \mathrm{pg} / \mathrm{ml}$ from min 10 through min 60 . The ratio of these levels to levels found during control studies averaged $3.0 \pm 0.5$, $2.7 \pm 0.4,2.5 \pm 0.4,2.2 \pm 0.3,2.4 \pm 0.3$, and $3.2 \pm 0.5$, respectively at the 10-, 20-, 30-, 40-, 50-, and 60-min sampling times. None of these ratios was significantly different from a theoretical value of 2.2. However, when all of the individual 42 ratios (six sample times in seven subjects) were analyzed together, their average $(2.7 \pm 0.2)$ was significantly greater than the desired ratio of $2.2(P<0.01)$ indicating a possible $22 \%$ overinfusion of glucagon.

During infusion of somatostatin plus glucagon, the profiles of plasma glucose, glucose appearance, and glucose disappearance after insulin administration were virtually identical to those observed in control studies in the same subjects except for a slight overshoot of each at 50-60 min which was not statistically significant. Plasma growth hormone responses remained suppressed. Plasma epinephrine, norepinephrine, and cortisol responses during infusion of somatostatin plus glucagon were not significantly different than those observed during control studies in contrast to the augmented responses in the circulating levels of these hormones that had been observed during infusion of somatostatin alone (Fig. 1).

Effect of infusion of phentolamine and propranolol $-\alpha$ - and $\beta$ - adrenergic blockade (Fig. 4). To determine the contribution of catecholamines to recovery of plasma glucose from insulin-induced hypoglycemia, phentolamine, an $\alpha$-adrenergic antagonist, and propranolol, a $\beta$-adrenergic antagonist, were infused together for $90 \mathrm{~min}$ in six subjects after administration of insulin in an attempt to produce combined $\alpha$ and $\beta$-adrenergic blockade. In the presence of these agents, neither the plasma glucose nadir nor the rate of recovery of plasma glucose differed significantly from that observed in control studies in the same subjects. Changes in glucose appearance, glucose disappearance, plasma glucagon, and plasma cortisol were also similar to those observed in the control experiments. However, plasma growth hormone and norepinephrine responses were significantly increased. Although plasma epinephrine responses were also greater than those observed in control studies, these differences were not statistically significant. Increases in heart rate accompanying hypoglycemia which had been observed in control studies did not occur during adrenergic blockade.

Effect of infusion of phentolamine, propranolol, and somatostatin-adrenergic blockade plus glucagon and growth hormone deficiency (Fig. 5). To evaluate the contribution of catecholamines to glucose counterregulation during glucagon (and growth hormone) deficiency, phentolamine and propranolol were infused along with somatostatin after insulin administration in the six subjects studied above. The combined administration of phentolamine, propranolol, and somatostatin further impaired glucose counterregulation after insulin administration compared to that already ob- 
served during infusion of somatostatin alone in the same subjects. Although the nadirs to which plasma glucose levels decreased after injection of insulin were similar during infusion of somatostatin with and without the adrenergic antagonists, subsequent recovery of plasma glucose from hypoglycemia was markedly depressed. Plasma glucose levels at min 90, just before stopping the phentolamine-propranolol-somatostatin infusion, averaged $52 \pm 6 \mathrm{mg} / \mathrm{dl}$ compared to $72 \pm 5 \mathrm{mg} / \mathrm{dl}$ observed during infusion of somatostatin alone $(P<0.01)$ and $92 \pm 3 \mathrm{mg} / \mathrm{dl}$ found in control studies $(P<0.001)$. This additional blunting of plasma glucose recovery was primarily due to further depression of the compensatory increase in glucose appearance, the peak value for which averaged only $1.93 \pm 0.40 \mathrm{mg} / \mathrm{kg}$ per min compared to $2.86 \pm 0.31 \mathrm{mg} / \mathrm{kg}$ per min observed during infusion of somatostatin alone $(P<0.01)$ and $3.34 \pm 0.41 \mathrm{mg} / \mathrm{kg}$ per min observed in

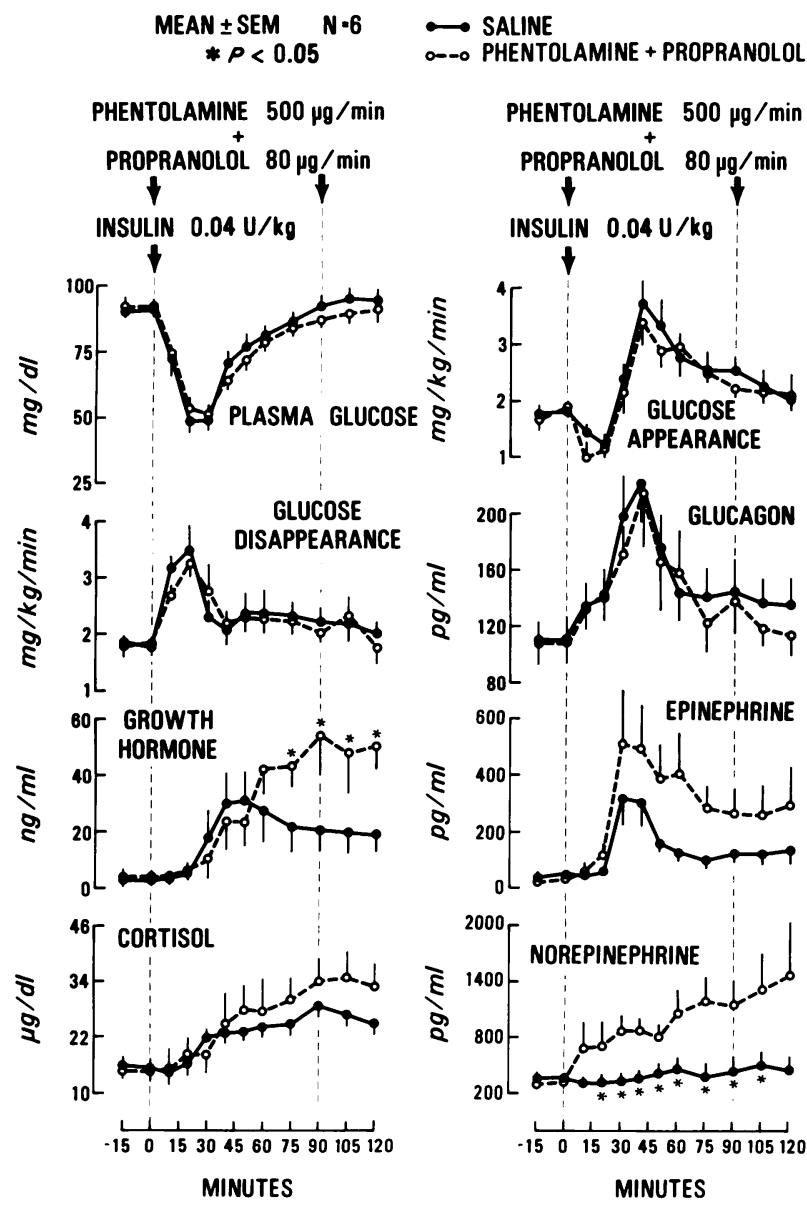

Figure 4 Effects of phentolamine and propranolol (combined $\alpha$ - and $\beta$ - adrenergic blockade) on plasma glucose, glucagon, growth hormone, cortisol, epinephrine, norepinephrine levels and the rates of glucose appearance and disappearance after insulin administration.

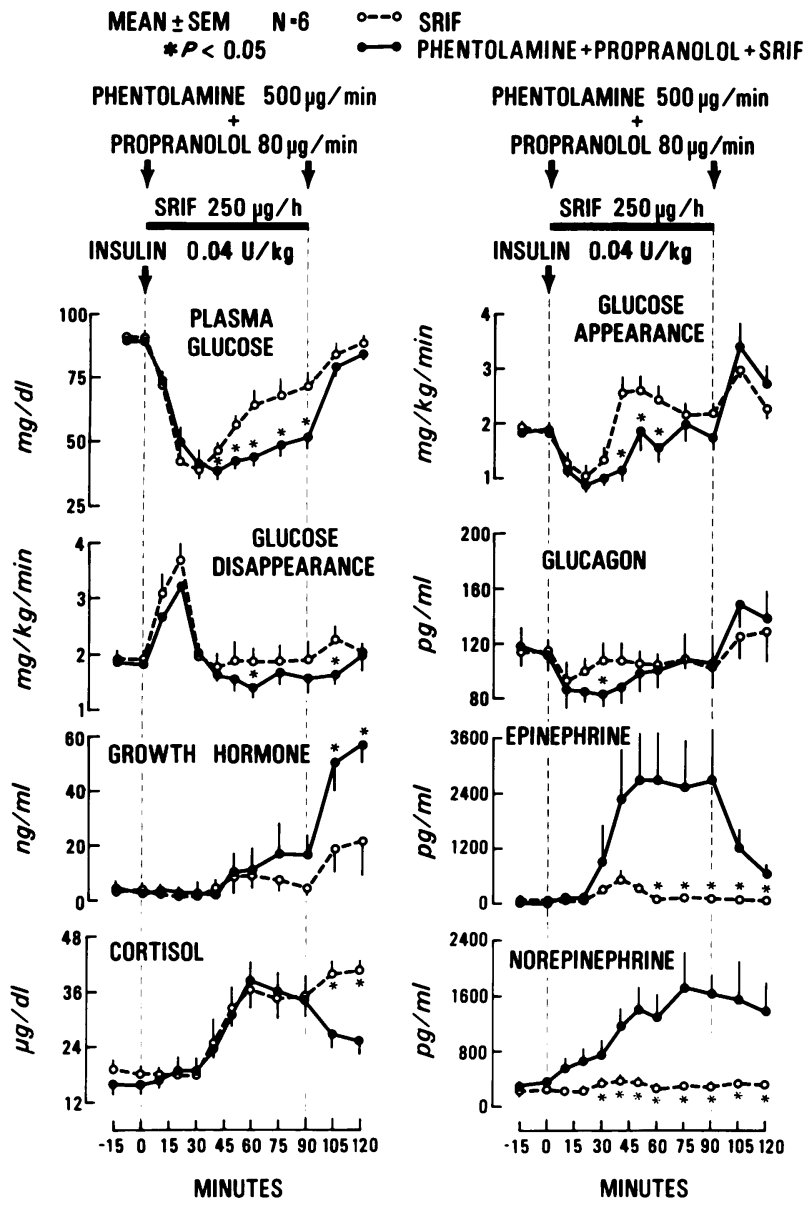

Figure 5 Comparison of plasma glucose, glucagon, growth hormone, cortisol, epinephrine, norepinephrine levels, and the rates of glucose appearance and disappearance after insulin administration during infusion of phentolaminepropranolol-somatostatin (SRIF) $\times$ (adrenergic deficiency plus glucagon and growth hormone deficiency) with those observed during infusion of somatostatin alone (glucagon and growth hormone deficiency).

control studies $(P<0.001)$. The initial suppression of glucose appearance and the initial increase in glucose disappearance after insulin administration were similar during infusion of somatostatin with and without the adrenergic antagonists. Glucose disappearance from min 50 through min 105 was consistently lower during infusion of somatostatin with the adrenergic antagonists than that observed during infusion of somatostatin alone.

During the 90-min infusion of somatostatin, propranolol, and phentolamine, plasma growth hormone and cortisol levels were not significantly different than those observed during infusion of somatostatin alone. After stopping the infusion of somatostatin plus phentolamine and propranolol, plasma levels of both hormones increased to values significantly $(P<0.01)$ 
greater than those observed during studies in which somatostatin alone had been infused. Plasma glucagon responses were suppressed comparably during infusion of somatostatin with and without the adrenergic antagonists; only at min 30 were plasma glucagon levels significantly different from those observed during infusion of somatostatin alone $(82 \pm 10$ vs. $110 \pm 7$ $\mathrm{pg} / \mathrm{ml}$, respectively $P<0.05)$. Plasma epinephrine and norepinephrine responses were six- to eightfold greater during infusion of somatostatin plus phentolamine and propranolol than during infusion of somatostatin alone.

\section{DISCUSSION}

In the present studies administration of insulin ( 0.04 $\mathrm{U} / \mathrm{kg}$, i.v.) lowered plasma glucose levels as a consequence of both inhibition of glucose appearance and stimulation of glucose disappearance, thus confirming similar observations in dogs $(28,29,34-36)$ and man $(9,36,37)$. As in these previous studies, glucose disappearance returned toward, but not below, base-line values whereas glucose appearance increased from its initially suppressed levels to nearly twice base-line values during recovery of plasma glucose from hypoglycemia. Thus, restoration of normoglycemia after insulin-induced hypoglycemia is primarily due to a compensatory increase in glucose production. Therefore, an analysis of the regulatory factors involved in glucose counterregulation should focus primarily on those factors which might rapidly stimulate hepatic glucose production. Both glucagon (6) and the catecholamines (5) can rapidly augment hepatic glucose production by stimulating glycogenolysis and gluconeogenesis. Although growth hormone and cortisol may increase glucose production by inducing hepatic insulin resistance to insulin (38), by altering substrate availability $(21,39,40)$ or by promoting enzyme induction $(8,21,40)$, neither hormone increases glucose production acutely (40); in fact, both hormones have been reported to decrease glucose production within the time frame of the present experiments $(41,42)$.

The hormonal secretory patterns and their relationships with the changes in rates of glucose appearance and disappearance in the present study are in substantial agreement with those reported by Garber et al. (9), the major difference being the demonstration of a significant increment in plasma glucagon before the onset of glucose counterregulation in the present study. The reason for this discrepancy is not clear but the present findings indicate that the temporal sequence of glucagon, epinephrine, cortisol, and growth hormone responses in relation to the compensatory increase in glucose appearance is compatible with a role for all these hormones in glucose counterregulation. Thus these temporal relationships by themselves do not per- mit precise definition of the individual contribution of any of these hormones.

Administration of somatostatin prevented both glucagon and growth hormone responses to insulin-induced hypoglycemia; plasma glucose decreased to a lower nadir than had been observed in control studies and recovery of plasma glucose to normoglycemia was attenuated. This impaired glucose counterregulation was due solely to a blunting of the compensatory increase in glucose appearance since glucose disappearance was not augmented. These effects of somatostatin on impairment of glucose counterregulation were attributable to suppression of glucagon rather than growth hormone responses. Infusion of somatostatin along with growth hormone, which elevated circulating growth hormone levels two- to threefold above those observed in control studies, did not reverse the effects of somatostatin whereas infusion of somatostatin along with glucagon completely reversed the effects of somatostatin-both those on plasma glucose recovery from hypoglycemia and, in particular, on glucose appearance. These results suggest that intact glucagon secretion is necessary for the normal compensatory increase in hepatic glucose production which is responsible for complete restoration of normoglycemia after insulin administration.

This conclusion, however, must be considered in view of the fact that circulating glucagon levels achieved in the above studies were two- to threefold greater than those observed in control studies. Based on previous reports $(32,33)$ indicating a portal-peripheral venous gradient for glucagon of $\cong 2.2$ during augmented glucagon secretion, the glucagon infusion rate of $3 \mathrm{ng} / \mathrm{kg}$ per min was chosen in an attempt to approximate the portal venous glucagon levels observed in the control studies, i.e. levels 2.2 times the peripheral venous glucagon levels observed in the control studies. At each of the six sampling points during the glucagon infusion the ratio of these values did not differ significantly from the desired theoretical value of 2.2. However, when all individual data (42 samples) were analyzed together, their mean (2.7) significantly exceeded the desired value, indicating a possible overinfusion of glucagon by as much as $22 \%$. This, coupled with the fact that glucagon infusions were begun at 0 time, may well explain the elevation of glucose concentrations to levels somewhat above the control values during somatostatin combined with glucagon. Nonetheless, the fundamental observation that glucagon administration prevented the somatostatin-induced impairment of glucose recovery from hypoglycemia, whereas growth hormone administration did not, remains.

Although the compensatory increase in glucose production and restoration of normoglycemia after insulin-induced hypoglycemia were impaired in the 
presence of somatostatin, it is notable that a compensatory increase in glucose appearance and partial recovery of plasma glucose from hypoglycemia did occur. This could have been due to epinephrine since augmented responses of this hormone occurred during the somatostatin studies and since plasma glucose recovery from insulin-induced hypoglycemia was totally prevented in similar studies performed in adrenalectomized patients (13). Furthermore, the fact that glucose disappearance was significantly decreased during the later portion of the somatostatin infusion compared to values in the control studies is also consistent with an epinephrine effect since epinephrine is known to decrease glucose clearance in man (43).

To evaluate the contribution of catecholamines in acute glucose counterregulation, both phentolamine, an $\alpha$-adrenergic antagonist, and propranolol, a $\beta$ adrenergic antagonist, were infused after insulin administration at doses conventionally used to achieve adrenergic receptor blockade. Although circulating epinephrine and norepinephrine levels observed during hypoglycemia were increased by this maneuver, infusion of these agents had no effects on glucose counterregulation. Similar results have been obtained with measurements of circulating glucose levels (15, 16) and glucose fluxes (17) in previous studies during selective $\alpha$ - or $\beta$-adrenergic blockade. These observations and those indicating that normal glucose recovery from insulin-induced hypoglycemia can occur in spinal cord transected $(10,11)$ and in adrenalectomized $(11-14)$ patients indicate that catecholamines are not essential for acute glucose counterregulation in man.

Nevertheless, as noted earlier glucocorticoid-treated adrenalectomized patients, who have normal glucose counterregulation after insulin-induced hypoglycemia, have virtually no recovery of plasma glucose from hypoglycemia during infusion of somatostatin (13). These observations suggest that catecholamines, particularly adrenomedullary epinephrine, may act primarily as a secondary line of defense against hypoglycemia which becomes critical when glucagon secretion is impaired. To evaluate this possibility, the effect of combined $\alpha$ - and $\beta$-adrenergic blockade along with somatostatin administration on glucose counterregulation was compared to the effects observed during infusion of somatostatin alone. Combined infusion of phentolaminepropranolol-somatostatin resulted in further impairment of recovery of plasma glucose from hypoglycemia compared to that observed during infusion of somatostatin alone and further blunting of the compensatory increase in glucose appearance. These results provide additional evidence that catecholamines may contribute to acute glucose counterregulation and that they may be especially important when glucagon secretion is impaired.
Finally, it should be pointed out that in these latter studies some glucose counterregulation was evident despite apparent adrenergic blockade and inhibition of both glucagon and growth hormone secretion; plasma glucose and glucose appearance increased respectively from nadirs of $36 \pm 2 \mathrm{mg} / \mathrm{dl}$ and $0.88 \pm 0.08$ $\mathrm{mg} / \mathrm{kg}$ per min to peak values of $52 \pm 5 \mathrm{mg} / \mathrm{dl}$ and $2.02 \pm 0.27 \mathrm{mg} / \mathrm{kg}$ per min. Several explanations are possible. Firstly, circulating epinephrine and norepinephrine levels were markedly increased to values in excess of 2.7 and $1.7 \mathrm{ng} / \mathrm{ml}$, respectively. The conventional doses of phentolamine and propranolol used in these studies have been shown to block the metabolic effects of epinephrine infused at a rate of $6 \mu \mathrm{g} / \mathrm{min}$ (44-46). This infusion rate has been reported to produce circulating epinephrine levels of $<1 \mathrm{ng} / \mathrm{ml}$ (47) which is below those seen in the present studies. Thus, since the adrenergic blocking agents used in the present study are competitive antagonists, it is possible that incomplete adrenergic blockade occurred due to the extreme elevation of both norepinephrine and epinephrine plasma levels. A second possible explanation is an intrinsic effect of hypoglycemia on the liver (48); increased glucose release from rat livers perfused in vitro has been observed after lowering glucose perfusate levels $(48,49)$. Finally, activation of sympathetic or parasympathetic innervation of the liver (50-53) and sympathetic inhibition of insulin secretion (54-56) could also have been involved. This latter effect would have permitted lower concentrations of counterregulatory factors to be more effective stimulants of glucose production and could have contributed along with hypoglycemia $(43,57)$, to the decrease observed in glucose disappearance. These sympathetic effects would have been possible if the doses of the adrenergic antagonists employed in the present study had been insufficient to completely block the effects of norepinephrine released from sympathetic nerve terminals within the liver.

In conclusion, the present studies indicate that in man: (a) restoration of normoglycemia after insulininduced hypoglycemia is primarily due to a compensatory increase in glucose production; $(b)$ intact glucagon, but not growth hormone, secretion is necessary for normal glucose counterregulation; and $(c)$ adrenergic mechanisms do not normally play an essential role in this process but become critical to recovery from hypoglycemia when glucagon secretion is impaired.

\section{ACKNOWLEDGMENTS}

The excellent technical assistance of K. Greene, B. Brick, J. King, R. Westland, W. Blanchard, and S. Shah is gratefully acknowledged. In addition, we are indebted to the General Clinical Research Center nursing staff for their superb help in the execution of these experiments, and to J. Hatteberg 
for her skillful editorial assistance in the preparation of this manuscript.

This project was funded in part by U. S. Public Health Service grants (AM20411, AM20837, AM05827, RR00585, AM20579, RR00036) and by grants from the Diabetic Children's Welfare Association/American Diabetes Association, Greater St. Louis Affiliate, and the Mayo Foundation, Rochester, Minn.

\section{REFERENCES}

1. Gerich, J. E., V. Schneider, S. E. Dippe, M. Langlois, C. Noacco, J. Karam, and P. Forsham. 1974. Characterization of the glucagon response to hypoglycemia in man. J. Clin. Endocrinol. Metab. 38: 77-82.

2. Vendsalau, A. 1960. Studies on adrenaline and noradrenaline in plasma. Acta Physiol. Scand. Suppl. 49. 173: $1-123$.

3. Roth, J., G. M. Glick, R. S. Yalow, and S. A. Berson. 1963. Hypoglycemia: a powerful stimulus to secretion of growth hormone. Science (Wash. D. C.). 140: 987-991.

4. Greenwood, F. C., J. Landon, and T. C. B. Stamp. 1966. The plasma sugar, free fatty acid, cortisol and growth hormone response to insulin. I. In control subjects. $J$. Clin. Invest. 45: 429-436.

5. Exton, J. H., G. A. Robison, E. W. Sutherland, and C. R. Park. 1971. Studies on the role of adenosine $3^{\prime}, 5^{\prime}$-monophosphate in the hepatic actions of glucagon and catecholamines. J. Biol. Chem. 246: 6166-6177.

6. Parrilla, R., M. N. Goodman, and C. J. Toews. 1974. Effect of glucagon: insulin ratios on hepatic metabolism. Diabetes. 23: 725-731.

7. Merimee, T. J., and D. Rabin. 1973. A survey of growth hormone secretion and action. Metab. Clin. Exp. 22: 1235-1253.

8. Baxter, J., and P. Forsham. 1972. Tissue effects of glucocorticoids. Am. J. Med. 53: 573-584.

9. Garber, A. J., P. E. Cryer, J. V. Santiago, M. W. Haymond, A. S. Pagliara, and D. M. Kipnis. 1976. The role of adrenergic mechanisms in the substrate and hormonal response to insulin-induced hypoglycemia in man. J. Clin. Invest. 58: 7-15.

10. Brodows, R. G., J. W. Ensinck, and R. G. Campbell. 1976. Mechanisms of plasma cyclic AMP response to hypoglycemia in man. Metab. Clin. Exp. 25: 659-663.

11. Palmer, J. P., D. P. Henry, J. W. Benson, D. G. Johnson, and J. W. Ensinck. 1976. The glucagon response to hypoglycemia in sympathectomized man. J. Clin. Invest. 57: 522-525.

12. Ensinck, J. W., R. M. Walter, J. P. Palmer, R. G. Brodows, and R. G. Campbell. 1976. Glucagon responses to hypoglycemia in adrenalectomized man. Metab. Clin. Exp. 25: 227-233.

13. Gerich, J., J. Davis, M. Lorenzi, R. Rizza, N. Bohannon, J. Karam, S. Lewis, S. Kaplan, T. Schultz, and P. Cryer. 1979. Hormonal mechanisms of recovery from hypoglycemia in man. Am. J. Physiol. 236: E380-E385.

14. Ginsburg, J., and A. Paton. 1956. Effects of insulin after adrenalectomy. Lancet. II: 491-494.

15. Walter, R. M., R. J. Dudi, J. P. Palmer, and J. W. Ensinck. 1974. The effect of adrenergic blockade on the glucagon responses to starvation and hypoglycemia in man.J. Clin. Invest. 54: 1214-1220.

16. Hokfelt, B., B. G. Hansson, L. G. Heding, and K. O. Nilsson. 1978. Effect of insulin induced hypoglycemia on the blood levels of catecholamines glucagon, growth hormone, cortisol, C-peptide, and proinsulin before and during medication with cardioselective beta-receptor block- ing agent metoprolol in man. Acta Endocrinol. 87: 659-667.

17. Clarke, W. S., J. V. Santiago, L. Thomas, M. W. Haymond, E. Ben-Galim, and P. E. Cryer. 1979. The role of adrenergic mechanisms in recovery from hypoglycemia in man: studies with adrenergic blockade. Am. J. Physiol. 236: E147-E152.

18. Christensen, N. J., S. E. Christensen, A. P. Hansen, and K. Lundbaek. 1975. The effects of somatostatin on plasma noradrenaline and plasma adrenaline concentrations during exercise and hypoglycemia. Metab. Clin. Exp. 24: 1267-1271.

19. Chideckel, E. W., J. Palmer, D. J. Koerker, J. Ensinck, M. B. Davidson, and C. J. Goodner. 1975. Somatostatin blockade of acute and chronic stimuli of the endocrine pancreas and the consequences of this blockade on glucose homeostasis. J. Clin. Invest. 55: 754-762.

20. Luft, R. E. Cerasi, and C. Hamberger. 1967. Studies on the pathogenesis of diabetes in acromegaly. Acta Endocrinol. 56: 593-598.

21. Cahill, G. F. 1971. Action of adrenal cortical steroids on carbohydrate metabolism. In The Human Adrenal Cortex. N. P. Christy, editor. Harper \& Row, Publishers, Inc., New York. 205-240.

22. Greenwood, F. C., and J. Landon. 1966. Assessment of hypothalamic pituitary function in endocrine disease. $J$. Clin. Pathol. (Lond.). 19: 284-292.

23. Feldman, J. M., J. W. Plonk, and C. H. Bivens. 1975. The role of cortisol and growth hormone in the counterregulation of insulin-induced hypoglycemia. Horm. Metab. Res. 7: 378-381.

24. Peake, G. T. 1974. Growth hormone. In Methods of Hormone Radioimmunoassay. B. M. Jaffe and H. R. Behrman, editors. Academic Press, Inc., New York, 103-121.

25. Faloona, G., and R. Unger. 1974. Glucagon. In Methods of Hormone Radioimmunoassay. B. Jaffe and H. Behrman, editors. Academic Press, Inc., New York. 317-330.

26. Murphy, B. E. P. 1967. Some studies of the proteinbinding of steroids and their application to the routine micro and ultramicro measurement of various steroids in body fluids by competitive protein-binding radioassay. $J$. Clin. Endocrinol. Metab. 27: 973-990.

27. Cryer, P. E., J. V. Santiago, and S. D. Shah. 1974. Measurement of norepinephrine and epinephrine in small volumes of human plasma by a single isotope derivative method: response to the upright posture. J. Clin. Endocrinol. Metab. 39: 1025-1029.

28. Wall, J. S., R. Steele, R. C. DeBodo, and N. Altszuler. 1957. Effect of insulin on utilization and production of circulating glucose. Am. J. Physiol. 189: 43-50.

29. DeBodo, R. C., R. Steele, N. Altszuler, A. Dunn, and J. S. Bishop. 1963. On the hormonal regulation of carbohydrate metabolism: studies with $\mathrm{C}^{14}$ glucose. Recent Prog. Horm. Res. 19: 445-488.

30. Radzuik, J., K. Norwich, and M. Vranic. 1974. Measurement and validation of nonsteady state turnover rates with applications to the insulin and glucose system. Fed. Proc. 33: 1841-1864.

31. Zar, J. H. 1974. Biostatistical Analysis. Prentice Hall Inc., Englewood Cliffs, N. J.

32. Dencker, H., P. Hedner, J. Holst, and K. Trandberg. 1975. Pancreatic glucagon response to a normal meal. Scand. J. Gastroenterol. 10: 471-474.

33. Blackard, W. G., N. C. Nelson, and S. S. Andrews. 1974. Portal and peripheral vein immunoreactive glucagon concentrations after arginine and glucose infusions. Diabetes. 23: 199-202. 
34. Cowell, J. W. F., and G. Hetenyi. 1969. The effect of phenoxybenzamine and propranolol and their combination on the restoration of glucose homeostasis after insulin induced hypoglycemia. Arch. Int. Pharmacodyn. Ther. 178: 412-422.

35. Cowan, J. S., and G. Hentenyi. 1971. Glucoregulatory responses in normal and diabetic dogs. Recorded by a new tracer method. Metab. Clin. Exp. 20: 360-372.

36. Cheng, J. S., and N. Kalant. 1970. Effects of insulin and growth hormone on the flux rates of plasma glucose and plasma free fatty acids in man. J. Clin. Endocrinol. Metab. 31: 647-653.

37. Perez, G., B. Trimarco, B. Ungaro, F. Rengo, and L. Sacca. 1978. Glucoregulatory response to insulin induced hypoglycemia in Laennee's cirrhosis. J. Clin. Endocrinol. Metab. 46: 778-782.

38. Kahn, R. C., I. D. Goldfine, D. M. Neville, and P. DeMeyts. 1978. Alternative in insulin binding induced by changes in vivo in the levels of glucocorticoids and growth hormone. Endocrinology. 103: 1054--1066.

39. Felig, P., E. B. Marliss, and G. F. Cahill. 1971. Metabolic response to human growth hormone during prolonged starvation. J. Clin. Invest. 50: 411-420.

40. Exton, J. H., L. E. Mallette, L. S. Jefferson, E. H. A. Wong, N. Friedmann, T. B. Miller, and C. R. Park. 1970. The hormonal control of hepatic gluconeogenesis. Recent Prog. Horm. Res. 26: 411-455.

41. Adamson, U., J. Wahren, and E. Cerasi. 1977. Influence of growth hormone on splanchnic glucose production in man. Acta Endocrinol. 86: 805-812.

42. LeCocd, F. R., D. Mebane, and L. L. Madison. 1964. The acute effects of hydrocortisone on hepatic glucose output and peripheral glucose utilization. J. Clin. Invest. 43: 237-246.

43. Rizza, R., M. Haymond, R. Cryer, and J. Gerich. 1978. Transient hepatic but peripheral effect on sustained hyperepinephrinemia in man. Clin. Res. 26: 684. (Abstr.)

44. Abramson, E. A., R. A. Arky, and K. A. Woeber. 1966. Effects of propranolol on the hormonal and metabolic responses to insulin-induced hypoglycemia. Lancet. II: 1386- 1389.
45. Robertson, R. P., and D. Porte. 1973. Adrenergic modulation of basal insulin secretion in man. Diabetes. 22: 1-8.

46. Gerich, J. E., M. Lorenzi, E. Tsalikian, and J. H. Karam. 1976. Studies on the mechanism of epinephrine-induced hyperglycemia in man. Diabetes. 25: 65-71.

47. Christensen, N. J., and K. G. M. M. Alberti. 1975. Plasma catecholamines and blood substrate concentrations: studies in insulin induced hypoglycemia after adrenalin infusion. Eur. J. Clin. Invest. 5: 415-423.

48. Hers, H. G. 1976. The control of glycogen metabolism in the liver. Annu. Rev. Biochem. 45: 167-189.

49. McCraw, E. F., M. J. Peterson, and J. Ashmore. 1967. Autoregulation of glucose metabolism in the isolated perfused rat liver. Proc. Soc. Exp. Biol. Med. 126: 232236.

50. Brodows, R. G., F. X. Pi-Sunyer, and R. C. Campbell. 1973. Neural control of counter-regulatory events during glucopenia in man. J. Clin. Invest. 52: 1841-1844.

51. Edwards, A. V., and M. Silver. 1972. Comparison of the hyperglycemic and glycogenolytic responses to catecholamines with those to stimulation of the hepatic sympathetic innervation in the dog. J. Physiol. (Lond.). 223: $571-593$.

52. Bloom, S. R., A. V. Edwards, and N. J. A. Vaughan. 1974. The role of the autonomic innervation in the control of glucagon release during hyperglycemia in the calf. $J$. Physiol. (Lond.). 236: 611-623.

53. Shimazu, T., and S. Ogasawara. 1975. Effects of hypothalamic stimulation on gluconeogenesis and glycolysis in the rat liver. Am. J. Physiol. 228: 1787-1793.

54. Woods, S., and D. Porte. 1974. Neural control of the endocrine pancreas. Physiol. Rev. 53: 596-619.

55. Sando, H., E. Miki, and K. Kosaka. Insulin secretion in hypoglycemia after adrenal vein ligature or splanchnectomy. Am. J. Physiol. 252: E237-242.

56. Miller, R., T. Ward, and M. Joyce. 1976. Direct neural inhibition of insulin secretion in response to systemic hypoglycemia. Am. J. Physiol. 230: 1090-1094.

57. Schultz, T., S. Lewis, D. Westbie, J. Gerich, R. Rushakoff, and J. Wallin. 1977. Glucose deliver - a clarification of its role in regulating glucose uptake in rat skeletal muscle. Life Sci. 20: 733-736. 